\title{
Comparison of norfloxacin versus nalidixic acid in therapy of acute urinary tract infections
}

LIISA K SELIN, MD, FRCP, GODFREY KM HARDING, MD, FRCP, MARGARET J THOMSON, RN, JAMES K KENNEDY, RT, BARBARA A URIAS, RT, ALLAN R RONALD, MD, FRCP

\begin{abstract}
Thirty-seven adult patients with acute urinary tract infections (UTI) were randomized to receive either a seven day (lower UTI) or a 14 day (upper UTI) course of norfloxacin $400 \mathrm{mg}$ orally twice daily, or nalidixic acid $1 \mathrm{~g}$ orally four times per day. Mean age, underlying disease and infecting organisms were similar in the two groups. Nine patients in the norfloxacin group and seven in the nalidixic acid group had presumptive evidence of upper UTI. Overall, 12 patients had antibody-coated bacteria-positive infections. The infecting organisms were: Escherichia coli (27), coagulase-negative staphylococci (four), Citrobacter freundii (three), Klebsiella pneumoniae (three), and Proteus mirabilis, Proteus vulgaris, Pseudomonas aeruginosa, Enterobacter agglomerans, Streptococcus agalactiae, Enterococcus faecalis (one of each). All of the organisms were susceptible to norfloxacin, while $81 \%$ were susceptible to nalidixic acid. The effects on the
\end{abstract}

periurethral and anal canal flora were similar in both groups. Five patients in each group experienced adverse clinical effects. The cure rates for norfloxacin and nalidixic acid were 79 and $83 \%$, respectively. There were two failures, two relapses and four reinfections in the norfloxacin group. In the nalidixic acid group, there were two failures, one relapse and four reinfections. One of the failure patients in the nalidixic acid group developed resistance to the drug, and two of the four reinfections were due to organisms resistant to nalidixic acid. In this patient population it was concluded that nalidixic acid may be as effective as norfloxacin in the treatment of acute, symptomatic UTI. Can J Infect Dis 1990;1(2):35-40

Key Words: Nalidixic acid, Norfloxacin, Urinary tract infection
$\mathrm{U}$ RINARY TRACT INFECTION (UTI) IS A COMMON CLINIcal problem, and individuals with recurrent infections can be especially difficult to treat because of antimicrobial resistance of the infecting organism. Newer oral agents are needed to

Departments of Medicine and Medical Microbiology. University of Manitoba; Division of Infectious Diseases, Health Sciences Centre; and Division of Infectious Diseases, St Boniface General Hospital, Winnipeg, Manitoba

Correspondence and reprints: Dr Liisa K Selin, University of Manitoba, Department of Medical Microbiology, RDU Laboratory, Room RR014, 820 Sherbrook Street, Winnipeg. Manitoba R3A 1 M3

Received for publication February 2, 1990. Accepted April 24,1990 treat these infections adequately. Norfloxacin, an oral quinolone carboxylic acid antimicrobial agent, has been shown to be very active in vitro against a wide variety of aerobic Gram-negative bacilli (including Pseudomonas aeruginosa) and Gram-positive organisms (including coagulasenegative staphylococci and enterococci) (1-3). It is well absorbed after oral administration and achieves active drug levels in urine approximately 100 times the serum level (4).

Norfloxacin is structurally related to nalidixic acid, which was introduced in 1964 as an antimicrobial agent with activity against Gram-negative bacilli (5). However, although efficacious, 
nalidixic acid use has been frequently associated with side effects or the emergence of resistant mutant strains (6-9).

This study was designed as a prospective, open, randomized comparison of the efficacy, tolerance and safety of orally administered norfloxacin and nalidixic acid in the therapy of acute UTI. The influence of these drugs on the microflora in the periurethral area and the anal canal was also compared.

\section{PATIENTS AND METHODS}

Patient selection: Outpatients of both sexes presenting to the authors' infectious disease clinics with clinical symptoms and signs of acute upper (fever, flank pain or tenderness) or lower (dysuria, urgency or frequency) UTI and significant bacteriuria were enrolled in this study. Patients with structural abnormalities were also enrolled. Significant bacteriuria was defined as a midstream urine culture bacterial count of greater than or equal to $10^{8}$ colony forming units (cfu)/L of urine. Significant pyuria was defined as greater than or equal to $10 \times 10^{6}$ leukocytes/L of urine (10). However, patients with counts of less than $10^{8} \mathrm{cfu} / \mathrm{L}$ but more than $10^{6} \mathrm{cfu} / \mathrm{L}$ with significant pyuria were also included $(11,12)$.

Patients were excluded if there was: a history of allergy to nalidixic acid; evidence of renal dysfunction (serum creatinine greater than $130 \mu \mathrm{mol} / \mathrm{L}$ ); a history of renal calculi (these patients are known to relapse); or pregnancy. In addition, patients known to be infected with organisms resistant to the study drug or who had had antimicrobial therapy less than $72 \mathrm{~h}$ before entry were excluded.

After written consent was obtained, the patients were stratified into either upper or lower UTI groups on the basis of clinical symptoms and/or antibody-coated bacteria testing if available. A randomization list for nalidixic acid and norfloxacin based on a table of random numbers was held in the hospital pharmacy. After stratification each patient was then randomized via the randomization list to receive either norfloxacin $400 \mathrm{mg}$ orally twice daily or nalidixic acid $1 \mathrm{~g}$ orally four times daily. The lower UTI were treated with a seven day course of therapy, while the upper UTI received a 14 day course.

Patient assessment: Patients were assessed clinically before therapy, during therapy at three to five days, and after the completion of therapy at days 5 to 9 and at four to six weeks. A midstream urine sample was obtained at each visit for quantitative bacterial culture and antimicrobial susceptibility testing. In female patients, swabs of the periurethral and anal canal areas were also similarly tested. Hematological and biochemical parameters of blood were also monitored for assessment of drug toxicity.

Bacteriology: An absolute leukocyte count and antibody-coated bacteria testing were performed on all urine samples as previously described (13). Midstream urine specimens and swabs of the periurethral area and the anal canal were cultured aerobically and processed as previously described (14). All organisms present were identified. Coagulase-negative staphylococci which were novobiocin-resistant were designated Staphylococcus saprophyticus. All other coagulase-negative staphylococci were designated Staph epidermidis. Antimicrobial susceptibility testing was performed by the disk diffusion method and by the agar dilution method for determination of minimal inhibitory concentrations (MICs) $(2,15,16)$. Biotyping of Escherichia coliwas performed to distinguish between reinfection and relapse (16).

Definitions: Cure was defined as improvement of symptoms and eradication of the pre-therapy infecting organism on follow-up culture. Failure was defined as continued presence of the pre-therapy infecting organism during therapy. Relapse was defined as recurrence of infection with the same organism less than four to six weeks after therapy, whereas reinfection was defined as recurrence of infection with a different organism after therapy.

Organisms were reported as antibody-coated bacteria-positive if there was uniform fluorescence of at least five bacteria per slide with a nonfluorescing negative control. Nonspecific fluorescence was reported if there was also fluorescence in the negative control and antibodycoated bacteria status could not be determined (12). Susceptibility to norfloxacin and nalidixic acid was defined as zone diameters of greater than 17 and greater than $19 \mathrm{~mm}$, respectively, or MICs of less than $16 \mathrm{mg} / \mathrm{L}$, or both.

Statistical analysis of proportions was carried out with the $\chi^{2}$ test with Yates' correction or with Fisher's exact test, and confidence intervals were calculated.

\section{RESULTS}

Forty symptomatic patients were entered and randomized to either treatment group (Table 1). In the nalidixic acid group, three patients were excluded from the data analysis: one was lost to follow-up after the first visit, another had an organism resistant to the randomly chosen antimicrobial agent, and the third was found to have bilateral renal calculi demonstrated on intravenous pyelography. A total of 33 patients had midstream urine bacterial counts greater than or equal to $10^{8} \mathrm{cfu} / \mathrm{L}$, and 29 of these had significant pyuria. Four patients had midstream urine bac- 
TABLE 1

\section{Characteristics of the population receiving norfloxacin} or nalidixic acid

\begin{tabular}{|c|c|c|}
\hline \multirow[b]{2}{*}{ Characteristic } & \multicolumn{2}{|c|}{ Treatment } \\
\hline & Norfloxacin & Nalidixic acid \\
\hline Number of patients entered & 19 & 21 \\
\hline Number of patients excluded & 0 & 3 \\
\hline Mean age (range) (years) & $46(19-77)$ & $47(19-76)$ \\
\hline $\operatorname{Sex}(M / F)$ & $1 / 18$ & $2 / 16$ \\
\hline$M S U \geq 10^{8} \mathrm{cfu} / \mathrm{L}$ & 15 & 18 \\
\hline $\mathrm{MSU}<10^{8} \mathrm{cfu} / \mathrm{L}$ & 4 & 0 \\
\hline \multicolumn{3}{|l|}{ Number of patients with pyuria } \\
\hline$\geq 10 \times 10^{6} \mathrm{WBC} / \mathrm{L}$ & 16 & 17 \\
\hline$<10 \times 10^{6} \mathrm{WBC} / \mathrm{L}$ & 2 & 1 \\
\hline Not done & 1 & 0 \\
\hline \multicolumn{3}{|l|}{ Antibody-coated bacteria } \\
\hline status & 6 & 6 \\
\hline Positive & 11 & 12 \\
\hline Negative & 1 & 0 \\
\hline $\begin{array}{l}\text { Nonspecific fluorescence } \\
\text { Not done }\end{array}$ & 1 & 0 \\
\hline \multicolumn{3}{|l|}{ Site of infection (clinical) } \\
\hline Upper tract & 9 & 7 \\
\hline Lower tract & 10 & 11 \\
\hline Adverse effects & 5 & 5 \\
\hline No. who discontinued drug & 4 & 2 \\
\hline
\end{tabular}

terial counts of less than $10^{8} \mathrm{cfu} / \mathrm{L}$; all of these had significant pyuria. They were all randomized to the norfloxacin treatment group.

In the norfloxacin group, there were five patients older than 65 years, and nine with three or more UTIs in the previous year. There were four patients with renal anomalies or previous surgical procedures: one malrotated right kidney; one previous right ureteric reflux with obstruction; one previous bladder surgery and left nephrectomy for chronic pyelonephritis; and one previous left nephrectomy for chronic pyelonephritis. A fifth patient had systemic lupus erythematosus which was being treated with prednisone. In the nalidixic acid group, there were five patients older than 65 years and seven with three or more UTIs in the previous year. There were three patients with complicating factors increasing their risk for recurrence: one duplex left kidney collecting system; one paraplegic using self-catheterization; and one patient with three previous bladder surgeries for incontinence and a history of chronic pyelonephritis.

In the norfloxacin and nalidixic acid upper UTI groups, five of six and four of six patients, respectively, had positive antibody-coated bacteria tests (12). The data on the infecting organisms are presented in Table 2. Escherichia coli was the most frequently recovered isolate, accounting for 27
TABLE 2

Infecting organisms with antimicrobial susceptibility

\begin{tabular}{|c|c|c|}
\hline \multirow[b]{2}{*}{ Infecting organism } & \multicolumn{2}{|c|}{ Patients susceptible/resistant } \\
\hline & Norfloxacin & Nalidixic acid \\
\hline Escherichia coli & $15 / 0$ & $12 / 0$ \\
\hline $\begin{array}{l}\text { Coagulase-negative } \\
\text { staphylococci }\end{array}$ & $3 / 0$ & $0 / 1$ \\
\hline Citrobacter freundii & $0 / 0$ & $3 / 0$ \\
\hline Proteus mirabilis & $1 / 0$ & $0 / 0$ \\
\hline Enterobacter agglomerans & $0 / 0$ & $1 / 0$ \\
\hline Pseudomonas aeruginosa & $1 / 0$ & $0 / 0$ \\
\hline Streptococcus agalactiae & $1 / 0$ & $0 / 0$ \\
\hline Enterococcus faecalis & $1 / 0$ & $0 / 0$ \\
\hline Klebsiella pneumoniae & $1 / 0$ & $2 / 0$ \\
\hline Proteus vulgaris & $0 / 0$ & $1 / 0$ \\
\hline
\end{tabular}

Some patients were infected with more than one organism. $n=19$ for norfloxacin: $n=18$ for nalidixic acid. $n$ Number of patients

(63\%) of all isolates, whereas coagulase-negative staphylococci accounted for four (9\%), Citrobacter freundii for three $(7 \%)$, and Klebsiella pneumoniae for three $(7 \%)$. In the norfloxacin group, all 19 were infected with organisms susceptible to norfloxacin, and six of these were infected with organisms resistant to nalidixic acid; the resistant organisms were Ps aeruginosa, Proteus mirabilis, Streptococcus agalactiae, Staph epidermidis (three), and $K$ pneumoniae. One patient was infected with two resistant organisms. In the nalidixic acid group, 18 patients were infected with an organism that was susceptible to nalidixic acid. One patient had Staph saprophyticus resistant to nalidixic acid but was cured. This patient was included in the study because she responded to therapy clinically before antimicrobial sensitivities were available, and although the organism was not sensitive to nalidixic acid by laboratory testing, the antibiotic appears to have been clinically efficacious. All of the organisms in the nalidixic acid group were sensitive to norfloxacin. Therefore, all isolates were susceptible to norfloxacin, and $35(81 \%)$ to nalidixic acid. The range of MICs for norfloxacin $(0.063$ to 4 $\mathrm{mg} / \mathrm{L}$ ) was much lower than for nalidixic acid ( 1 to greater than $128 \mathrm{mg} / \mathrm{L}$ ).

In the norfloxacin group, 15 of 19 patients or $79 \%$ (95\% confidence interval 61 to 97 ) were cured of their initial infections compared with 15 of 18 or $83 \%$ (95\% confidence interval 66 to 100 ) in the nalidixic acid group. This difference was not significant $(\mathrm{P}=0.54)$. Of the patients designated as cures, four in each treatment group developed reinfection with different organisms. Also, one patient in each group received only one week of follow-up. All of the other patients had four to six weeks of follow-up. There were two failures and two relapses in the norfloxacin group, while the 
nalidixic acid group had two failures and one relapse. In the norfloxacin group, five of these eight patients had histories of multiple recurrent infections, and one relapse had a history of previous nephrectomy and chronic pyelonephritis. One relapse received nine days of therapy, and one failure one day; both discontinued therapy due to side effects. In the nalidixic acid group, all five reinfections and relapses had histories of multiple recurrent UTI. The two patients who failed therapy did not take complete courses of therapy (one discontinued therapy after two days and the other after three) due to side effects.

Of the two patients in the norfloxacin treatment group who failed therapy, one presented with an upper UTI with significant pyuria; the initial urine culture grew two antibody-coated bacteria-negative organisms, Strep agalactiae and Staph epidermidis (three), both at $6 \times 10^{7} \mathrm{cfu} / \mathrm{mL}$. Both organisms were sensitive to norfloxacin and resistant to nalidixic acid. One week after discontinuation of treatment the patient was symptomatic and the urine culture grew Strep agalactiae greater than $10^{8} \mathrm{cfu} / \mathrm{L}$ which was still sensitive to norfloxacin. The other patient who failed therapy had a history of recurrent UTI and presented with a lower UTI. The initial urine culture showed $E$ coli with significant pyuria, sensitive to both study antimicrobial agents. This patient only took three pills and discontinued therapy due to side effects. The repeat urine grew the same biotype of $E$ coli, still sensitive to both antimicrobial agents. The two relapses with norfloxacin occurred in two patients with $E$ coli upper UTI, antibody-coated bacteria test positive and long histories of recurrent infections. One of the patients took only nine days of therapy due to medication side effects. For both patients the organism was sensitive to both antimicrobial agents, and remained so at relapse.

The two patients in the nalidixic acid group who failed therapy discontinued their medication early due to side effects. One patient had an upper UTI with antibody-coated bacteria-positive $E$ coli but discontinued therapy after three days. At this time she still had symptoms and the urine culture grew the same biotype of antibody-coated bacteriapositive $E$ coli which had become resistant to nalidixic acid. The second patient had a lower UTI with $K$ pneumoniae, but discontinued therapy after $48 \mathrm{~h}$. She remained symptomatic and her urine culture still showed $K$ pneumoniae greater than $10^{8} \mathrm{cfu} / \mathrm{L}$ sensitive to nalidixic acid. The one patient who relapsed after nalidixic acid therapy for a lower tract $E$ coli infection had a history of multiple infections in the previous year. When relapse occurred, the $E$ coli retained its susceptibility to nalidixic acid.
Of the 12 patients with infecting organisms which were antibody-coated bacteria test positive, six of six were cured with norfloxacin, and five of six with nalidixic acid. The one patient who was not cured did not take a full course of therapy. All three patients with positive antibody-coated bacteria tests who received the seven day course of therapy were cured. Among patients treated as upper UTI, eight of nine were cured with norfloxacin and six of seven with nalidixic acid. Therefore, in the norfloxacin group nine of 10 patients diagnosed as having upper UTI either clinically or by antibody-coated bacteria testing were cured, and in the nalidixic group eight of nine such patients were cured. However, one of the nine patients with an upper UTI in the norfloxacin group had a reinfection six weeks after completing therapy. The reinfecting organism was $E$ coli. Three of eight patients with an upper UTI in the nalidixic acid group had reinfections at six days and four and five weeks, respectively, after completion of therapy. The reinfecting organisms were $E$ coli in two of the patients and an alphahemolytic streptococcus in the third. All of the reinfecting organisms were sensitive to norfloxacin; however, one of the nalidixic acid-treated patients developed an infection that was resistant to nalidixic acid (alpha-hemolytic streptococcus).

In the norfloxacin group three of 10 patients with lower UTI had reinfections occurring at nine days and four and five weeks, respectively, after therapy was discontinued. The reinfecting organisms were $E$ coli, $K$ pneumoniae, and Strep agalactiae, all of which were sensitive to norfloxacin, but the $K$ pneumoniae and the Strep agalactiae were resistant to nalidixic acid. In the nalidixic acid group only one of the 11 patients with lower UTI had reinfections, which occurred five weeks after completion of therapy. This was due to Enterococcus faecalis resistant to both antimicrobial agents.

Serial cultures from the periurethral area and the anal canal were obtained from 15 patients in the norfloxacin group and 12 in the nalidixic acid group (Table 3). However, since some of the patients were infected with more than one organism, there was a total of 18 and 13 organisms assessed in the norfloxacin and nalidixic acid groups, respectively. The infecting organism was eradicated from the periurethral flora in 10 of 13 cases $(77 \%)$ in the norfloxacin group and seven of 10 cases $(70 \%)$ in the nalidixic acid group $(\mathrm{P}=0.54)$. Eradication of the infecting organism from anal canal flora occurred in seven of 11 cases (64\%) treated with norfloxacin and in five of eight cases $(62 \%)$ treated with nalidixic acid $(\mathrm{P}=0.70)$. Three of the four patients in the norfloxacin group 
TABLE 3

Influence of norfloxacin and nalidixic acid on microflora in the periurethral area and the anal canal

\begin{tabular}{|c|c|c|c|c|c|}
\hline \multirow[b]{2}{*}{ Treatment } & \multirow{2}{*}{$\begin{array}{l}\text { Serial cultures obtained } \\
\text { (Number of patients) }\end{array}$} & \multicolumn{2}{|c|}{ Infecting organism present* } & \multicolumn{2}{|c|}{ Infecting organism eradicated ${ }^{\dagger}$} \\
\hline & & Periurethral area & Anal canal & Periurethral area & Anal canal \\
\hline Norfloxacin & 15 & $13(87 \%)$ & $11(73 \%)$ & $10(77 \%)$ & $7(64 \%)$ \\
\hline
\end{tabular}

Values are number of patients. "There were four patients with two infecting organisms, one or both of which were present. ${ }^{\dagger}$ In patients who had two infecting organisms present in either area, both had to be eradicated

who had reinfections were noted to have the reinfecting organism present in their flora either during therapy or at the time of reinfection. All four patients in the nalidixic acid group who had reinfections had the organism present in their flora.

There were five patients in each group who experienced adverse clinical effects. The main complaints in the norfloxacin group included: nausea, severe headache, presyncope and vaginitis. In the nalidixic acid treatment group the main adverse effects complained of were headache, nausea, epigastric pain, emotional lability and vaginitis. There were no biochemical or hematological abnormalities noted in the 37 patients throughout the study.

\section{DISCUSSION}

The results of this trial in this small patient population suggest that nalidixic acid may be as efficacious as norfloxacin in the therapy of patients with acute, symptomatic upper or lower UTI. However, it is recognized that due to the small number of subjects enrolled in each arm, there was a very large beta error.

Patients with upper UTI showed similar responses to both drugs. In the norfloxacin group, nine of 10 such patients (90\%) were cured, and in the nalidixic acid group, eight of nine $(89 \%)$ were cured. Since this study had a high proportion of patients with a history of multiple recurrent infections and underlying diseases which increased their risk of recurrence, the cure rate of $79 \%$ with norfloxacin therapy is slightly less than the author's previous study in normal females with acute upper and lower UTIs (10). Furthermore, in both groups the majority of failures occurred in patients who did not complete their course of therapy due to side effects. In the norfloxacin group, one of two failures, and in the nalidixic acid group, both failures, took their medications for less than $48 \mathrm{~h}$. This cure rate is comparable to other studies in the literature using norfloxacin in complicated and uncomplicated UTI (18-20). Comparative trials of norfloxacin and nalidixic acid have demonstrated similar results with relatively equal efficacy of both drugs, although these studies also had small numbers of patients (2122 ). In the present study, the percentage of patients who developed reinfections was 21 for those who received norfloxacin and 22 for those who received nalidixic acid. This high frequency of reinfection reflects the study population, which had a high percentage of individuals with a history of recurrent infection (23).

This study also confirms the previous observation that norfloxacin has a broader spectrum of activity against Gram-negative and Gram-positive urinary pathogens than nalidixic acid (1-3). All of the organisms at the beginning of this study were susceptible to norfloxacin, including Gram-positive pathogens (four coagulase-negative staphylococci, one E faecalis and one Strep agalactiae) and three Gram-negative pathogens ( $K$ pneumoniae, $P$ s aeruginosa and $P$ mirabilis) which were all resistant to nalidixic acid.

Norfloxacin and nalidixic acid were similar in their abilities to eradicate the infecting organisms from flora in the periurethral area and anal canal (Table 3). It may be significant that two of the four reinfections in the nalidixic acid group were due to organisms resistant to nalidixic acid. These two patients also had nalidixic acid-resistant organisms concomitantly present in the flora of the periurethral area and the anal canal. Also, the infecting organism in one of the patients who failed therapy with nalidixic acid developed resistance. None of the patients who were considered failures (two), relapses (two) or reinfections (four) in the norfloxacin group became infected with an organism which was resistant to norfloxacin.

Both drugs were equally well tolerated with major side effects in two patients in the norfloxacin group and in three in the nalidixic acid group. These side effects were similar for the two drugs and included symptoms of nausea, headache and abdominal pain. The overall rate of side effects for both drugs was $26 \%$, which is consistent with the literature $(20,21,24)$.

The clinical response of patients to therapy with norfloxacin correlated well with the in vitro susceptibility data and demonstrated that this drug should be a useful adjunct to the treatment of UTI caused by a variety of Gram-negative and Gram- 
positive organisms. This study further supports previous reports (25-27) that norfloxacin is an effective antimicrobial agent in the treatment of individuals with acute symptomatic upper and lower UTIs, even in those with multiple recurrences or underlying diseases.

ACKNOWLEDGEMENTS: This investigation was supported by a grant-in-aid from Merck Frosst Inc, Dorval, Quebec.

\section{REFERENCES}

1. Gadebusch HH, Shungu DL, Weinberg E, Chung SK. Comparison of the antibacterial activity of norfloxacin (MK-0366, AM-715), a new organic acid, with that of other orally absorbed chemotherapeutic agents. Infection 1982;10:41-4.

2. Haase DA, Urias BA, Harding GKM, Ronald AR. Comparative in vitro activity of norfloxacin against urinary tract pathogens. Eur J Clin Microbiol 1983;2:235-41.

3. Newson SWB. The antimicrobial spectrum of norfloxacin. J Antimicrob Chemother 1984; 13(Suppl B):25-31.

4. Wise R. Norfloxacin - A review of pharmacology and tissue penetration. J Antimicrob Chemother 1984; 13(Suppl B):59-64.

5. Lesher GY, Froelich EJ, Gruett MD, Bailey JH, Brundage RP. 1,8-naphthyridine derivatives. A new clan of chemotherapeutic agents. J Med Pharm Chem 1962;5:1063-5.

6. Ronald AR, Turck M, Petersdorf RG. A critical evaluation of nalidixic acid in urinary tract infections. N Engl J Med 1966;275:1081-9.

7. Greenwood D, O'Grady F. Factors governing the emergence of resistance to nalidixic acid in treatment of urinary tract infections. Antimicrob Agents Chemother 1977; 12:678-81.

8. Preiksaitis JK, Thompson L, Harding GKM, Marrie TJ, Hoban S, Ronald AR. A comparison of the efficacy of nalidixic acid and cephalexin in bacteriuric women and their effect on fecal and periurethral carriage of Enterobacteriaceae. $\mathrm{J}$ Infect Dis 1984;143:603-8.

9. Duckworth GJ, Williams JD. Frequency of appearance of resistant variants to norfloxacin and nalidixic acid. J Antimicrob Chemother 1984; 13(Suppl B):33-8.

10. Stamm WE, Counts GW, Running KR, Fihn W, Turck M. Holmes KK. Diagnosis of coliform infection in acutely dysuric women. N Engl J Med 1982;307:463-8.

11. Platt R. Quantitative definition of bacteriuria. Am J Med 1983;75:44-52.

12. Harding GKM, Marrie TJ, Ronald AR, Hoban S, Muir P. Urinary tract localization in women. JAMA 1978;240:1 147-50.

13. Harding GKM, Ronald AR. A controlled study of antimicrobial prophylaxis of recurrent urinary infection in women. N Engl J Med 1974;291:597-601.
14. Steers E, Foltz EL, Graves BL. An inocula replicating apparatus for routine testing of bacterial susceptibilities to antibiotics. Antibiotic Chemother 1959;9:307-11.

15. National Committee for Clinical Laboratory Standards. Performance standards for antimicrobic disk susceptibility tests. Approved standard ASM-2, 2nd edn. Villanova, Pennsylvania: National Committee for Clinical Laboratory Standards, 1979.

16. Buckwold FJ, Ronald AR, Harding GKM, Marrie TJ, Fox L, Cates C. Biotyping of Escherichia coli by a simple multiple-inoculation agar plate technique. J Clin Microbiol 1979;10:275-8.

17. Haase DA, Harding GKM, Thomson MJ, Kennedy JK, Urias BA, Ronald AR. Comparative trial of norfloxacin and trimethoprim-sulfamethoxazole in the treatment of women with localized, acute, symptomatic urinary tract infection and antimicrobial effect on periurethral and fecal microflora. Antimicrob Agents Chemother 1984;26:481-4.

18. Kirby CP. Treatment of urinary tract infection in general practise with a 3-day course of norfloxacin. J Antimicrob Chemother 1984;13(Suppl B):107-12.

19. Schaeffer AJ, Sisney GA. Efficacy of norfloxacin in urinary tract infections - Biological effects on vaginal and fecal flora. J Urol 1985; 133:628-30.

20. Boerma JBJ, Van Saene HKF. Norfloxacin treatment in complicated urinary tract infection. Scand J Infect Dis 1986;VOL(Suppl 48):20-6.

21. Reeves DS, Lacey RW, Mummery RM, Mahendrda M, Bint AJ, Newsom SWB. Treatment of acute urinary infection by norfloxacin or nalidixic acid/citrate: A multi-centre comparative study. J Antimicrob Chemother 1984;13(Suppl B):99-105.

22. Sabbour MS, El Bokl MA, Osman LM. Experience on the efficacy and safety of nalidixic acid, oxolinic acid, cinoxacin and norfloxacin in the treatment of urinary tract infections. Infection $1984 ; 12: 377-80$.

23. Brumfitt W, Hamilton-Miller JMT. A review of urinary infection management and the evaluation of a potential new antibiotic. J Antimicrob Chemother 1984;13(Suppl B):121-33.

24. Vogel R, Deaney NB, Round EM, Vandenburg MJ, Currie JC. Norfloxacin, amoxycillin, co-trimoxazole and nalidixic acid. A summary of 3-day and 7-day therapy studies in the treatment of urinary UTIs. J Antimicrob Chemother 1984; 13(Suppl B): 1 13-20.

25. Leigh DA, Smith EC, and Marriner J. Comparative study using norfloxacin and amoxicillin in the treatment of complicated urinary tract infections in geriatric patients. J Antimicrob Chemother 1984; 13(Suppl B):79-83.

26. Sabbaj J, Hoagland VL, Cook T. Norfloxacin versus co-trimoxazole in the treatment of recurring urinary tract infections in men. Scand $J$ Infect Dis 1986;VOL(Suppl 48):48-53.

27. Watt B, Chait I, Kelsey MC, et al. Norfloxacin versus cotrimoxazole in the treatment of uncomplicated urinary tract infections - A multicentre trial. J Antimicrob Chemother 1984;13(Suppl B):89-94. 


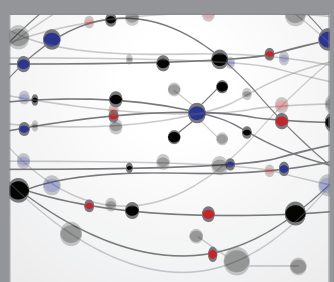

The Scientific World Journal
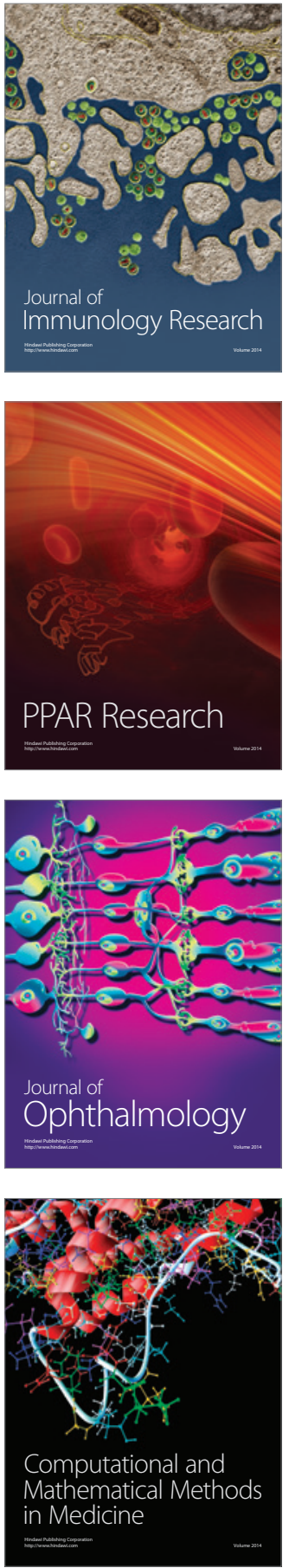

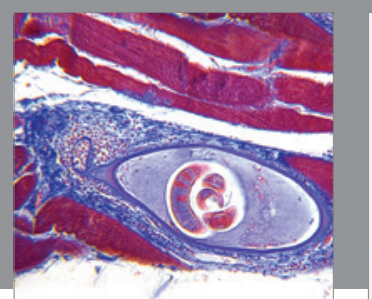

Gastroenterology Research and Practice

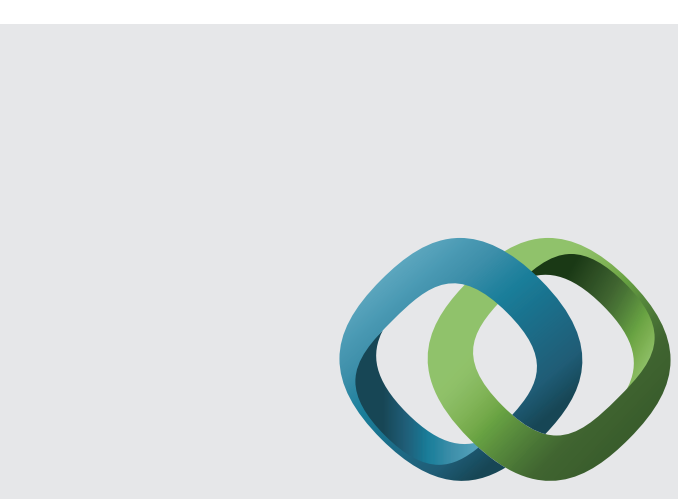

\section{Hindawi}

Submit your manuscripts at

http://www.hindawi.com
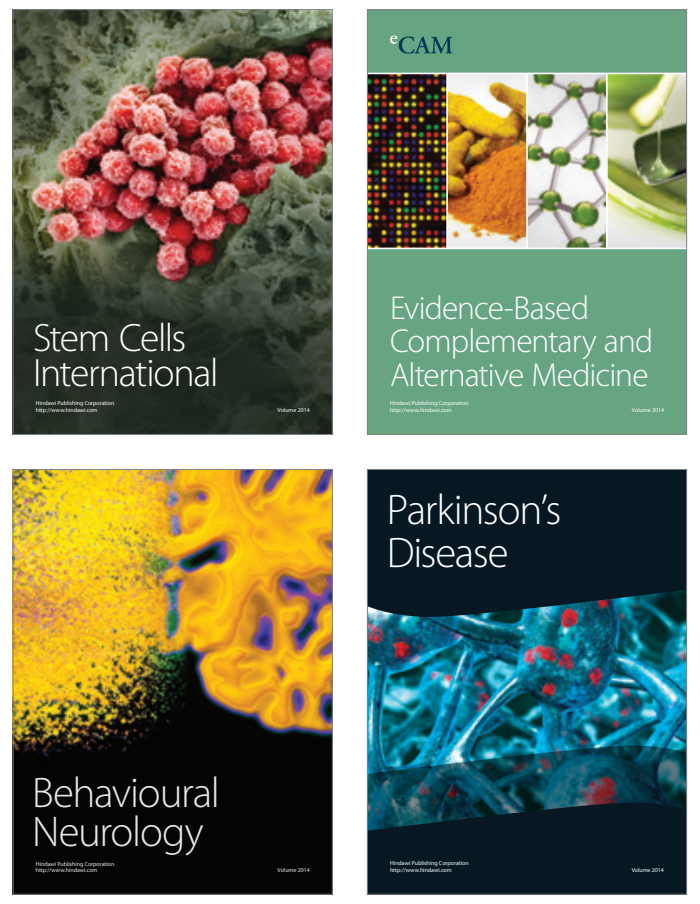
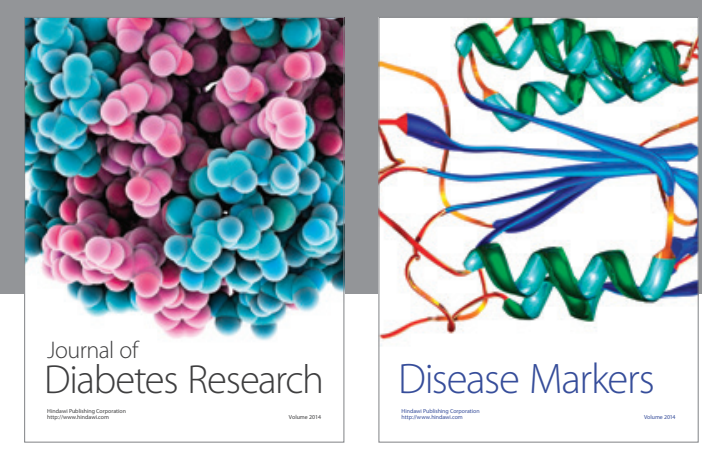

Disease Markers
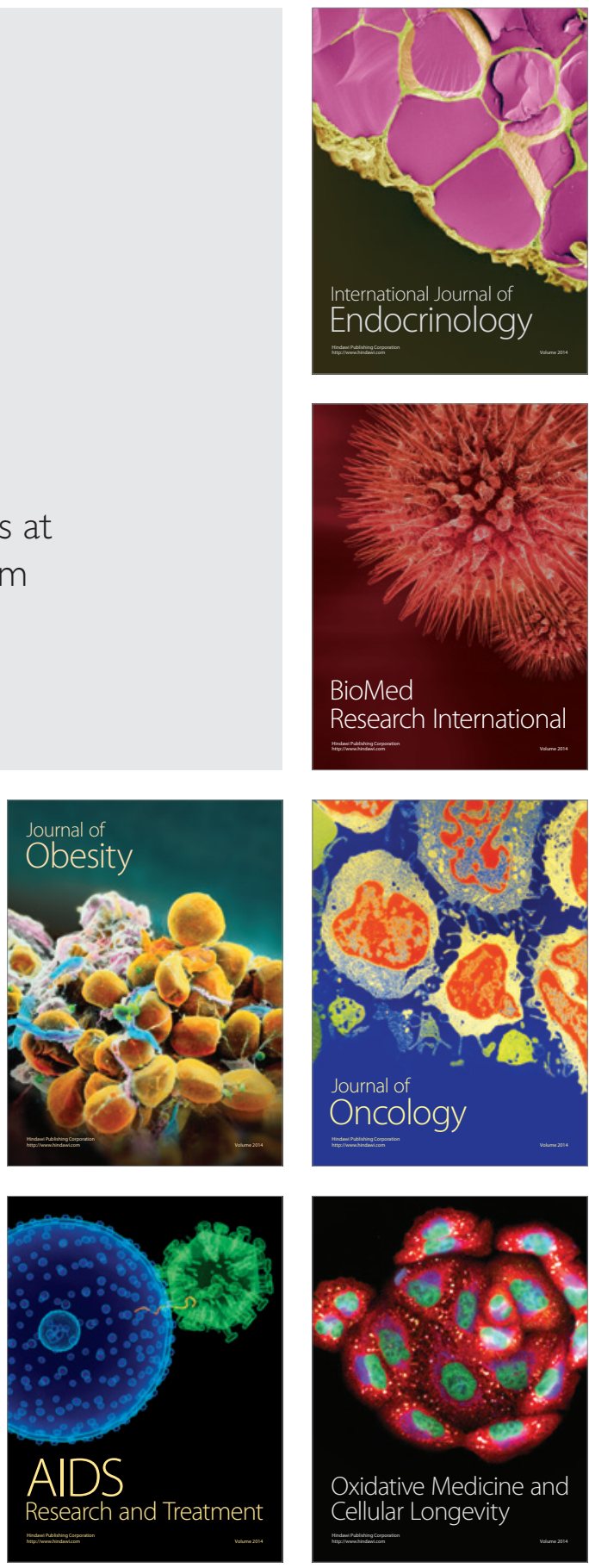